\title{
Evaluation of Antianxiety Effect of Oxytocin in Rats
}

\author{
K. Raadhika ${ }^{1}$, M. Malathi ${ }^{2}$ \\ ${ }^{1}$ Associate Professor, Institute of Pharmacology, Madurai Medical College, Madurai, India \\ ${ }^{2}$ Assistant Professor, Institute of Pharmacology, Madurai Medical College, Madurai, India
}

\begin{abstract}
Aim: To evaluate the anti-anxiety effect of oxytocin in male rats using elevated plus maze. Materials and Methods:18 male rats were randomly allocated into three groups of six animals each. Rats in group 1 served as control and received distilled water intraperitonealy. Group 2 served as standard and received Diazepam $2 \mathrm{mg} / \mathrm{kg}$ ip, the $3^{\text {rd }}$ group received oxytocin $4 \mathrm{mcg} / \mathrm{kg}$ ip. Each of the eighteen rats is placed individually at the center of elevated plus maze and observed for five minutes. Preference for first entry, number of entries into the open and closed arms and time spent in each arm of the maze will be recorded. One hour after drug administration the experiment is repeated and results tabulated and analyzed using suitable statistical method. Results: The time spent in open arm is increased in oxytocin treated group when compared with control and is comparable to diazepam.Conclusion: The findings in this study suggest that oxytocin possess Antianxiety activity and various studies has shown that oxytocin acts by inhibiting the amygdala through GABA receptors like diazepam. Further studies and researches are needed to optimize the dose and use it as a novel antianxiety agent.
\end{abstract}

Keywords: Anxiety, oxytocin, open arm, elevated plusmaze, GABA, Amygdala

\section{Introduction}

Oxytocin is a medication and hormone. ${ }^{1}$ It was discovered in $1952^{2}$, It is on the WHO's list of essential medicines the most important medication needed in basic health system ${ }^{3}$. Oxytocin is normally produced in the hypothalamus and stored in the posterior pituitary gland. ${ }^{4,5}$. It is released due to stretching of cervix and uterus during labour and with stimulation of nipples from breast feeding.This help with birth, bonding with the baby, and milk production ${ }^{5,6}$. It plays a role in social bonding, sexual reproduction in both sexes, and during and after childbirth.

Studies have looked at oxytocin's role In various behaviors including orgasm, social recognition, pair bonding, anxiety, and maternal behaviours. ${ }^{7}$ Behavioral effects is due to release from centrally projecting oxytocin neurons and is different from those that project from pituitary. ${ }^{8}$

Oxytocin receptors are expressed in neurons of many parts of brain and spinal cord including the amygdala ventromedial hypothalamus, septum, nucleus accumbens and brain stem. It evokes feelings of contentment, reduction in anxiety and feelings of calmness and security. This shows Oxytocin may be important for inhibition of brain regions associated with behavioral effects, stress, fear and anxiety. Research demonstrates that Oxytocin can decrease anxiety and protects against stress. Nasally administered oxytocin is reported to reduce fear possibly by inhibiting amygdala (which is thought to be responsible for fear response).Studies in rodents has shown oxytocin can efficiently inhibit fear responses by activating an inhibitory circuit with in amygdala ${ }^{9}$

Anxiety and fear are normal emotions with great adaptive value that have been selected along the evolutionary process. While fear occurs in response to specific threats, the source of anxious behavior is usually undefined or unknown. In contrast to normal/adaptive anxiety, anxiety disorders affect the individual performance of daily life tasks, ${ }^{10}$ representing a high cost for public health care all over the world. ${ }^{11}$ Hence there is a continuous search for an ideal anxiolytic.

The present study was proposed to evaluate anxiolytic effects of oxytocin in comparison with diazepam using elevated plus maze.

\section{Materials and Methods}

Oxytocin: $2 \mathrm{mcg} /$ unit. Each ampoule containing $1 \mathrm{ml} / 5 \mathrm{u} / 10$ mcg

Diazepam: Each ampoule contains $5 \mathrm{mg} / \mathrm{ml}$.

Animals:

Albinorats were obtained from the animal house of the Institute of Pharmacology, Madurai Medical College Madurai. Animals were preconditioned in the lab for one week before the experiment to get accustomed to the laboratory condition. They were allowed free access to food and water under a 12 hour light dark cycle. The animal procedures have been approved and prior permission from Institutional ethical committee was obtained as per prescribed guidelines.

\section{Procedures}

\section{Elevated plus maze}

The elevated plus maze (EPM), perhaps the most employed animal model of anxiety in current practice, was first proposed by Handley \& Mithani ${ }^{12}$ and further validated by File et al. ${ }^{13}$ The apparatus is raised $50 \mathrm{~cm}$ above floor level, and is composed of two enclosed arms $(50 \mathrm{~cm} \times 10 \mathrm{~cm} \mathrm{x}$ $40 \mathrm{~cm})$ opposed perpendicularly by two open arms $(50 \mathrm{~cm} \mathrm{x}$ $10 \mathrm{~cm}),($ picture 1)

The test is based on the natural tendency of rodents to explore novel environments and their innate avoidance of unprotected, bright, and elevated places (represented by the open arms).

\section{Volume 5 Issue 5, May 2016}




\section{International Journal of Science and Research (IJSR) \\ ISSN (Online): 2319-7064}

Index Copernicus Value (2013): 6.14 | Impact Factor (2015): 6.391

Physiological signs of stress are confinement to the closed arms, increased defecation and increased cortisol level, ${ }^{13}$ whereas exposure to classical anxiolytic drugs, such as benzodiazepines, increases exploration of these arms. ${ }^{13}$

Picture 1

ELEVATED PLUS MAZE - STANDARD FOR RAT

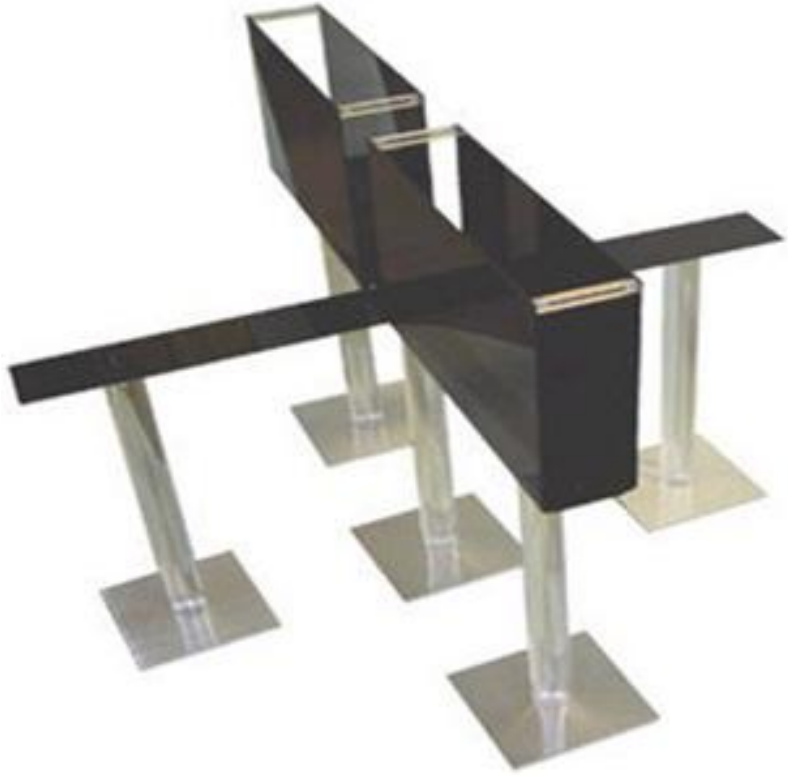

The animals were divided into three groups each group containing six animals $(n=6)$

Table 1

\begin{tabular}{|c|c|c|}
\hline $\begin{array}{c}S . \\
N O\end{array}$ & Group & Treatment \\
\hline 1 & Control & Normal food and water + distilled water ip \\
\hline 2 & Standard & $\begin{array}{c}\text { Normal food and water + Diazepam } \\
2 \mathrm{mg} / \mathrm{Kg} \text { - ip }\end{array}$ \\
\hline 3 & Test & $\begin{array}{c}\text { Normal food and water }+ \text { Oxytocin } 4 \mathrm{mcg} / \mathrm{Kg} \\
\text { ip }\end{array}$ \\
\hline
\end{tabular}

Animals are treated accordingly and after one hour of drug administration the rats are placed at the centre of plus maze facing towards open arm. The animals were observed for five minutes and experiment was video recorded. The preference of the animal for the first entry, number of entries into the open and closed arm and time spent in both arms are recorded and tabulated.

\section{Results}

The effects of oxytocin (4 mcg/ $\mathrm{kg}$-ip) and diazepam $(2 \mathrm{mg} / \mathrm{Kg}$ - ip) resulted in significant increases in the total number of entries into the open arms as in Figure 1.

Significant increase in the duration of time spent in the open arm was observed in oxytocin $(4 \mathrm{mcg} / \mathrm{kg})$ treated rats compared with control $(\mathrm{p}<0.001)$ and is comparable to that of Diazepam as in figure 2..Diazepam produce a lowest number of entries in the closed $\operatorname{arm}(\mathrm{p}<.001)$ while control had the highest closed arm entry value of (Figure 3 ) Number of entries in closed arm produced by Oxytocin has also decreased when compared with $\operatorname{control}(\mathrm{p}<0.001)$ as in figure. The time spent in closed arm did not have significant change in oxytocin treated group compared with diazepam.

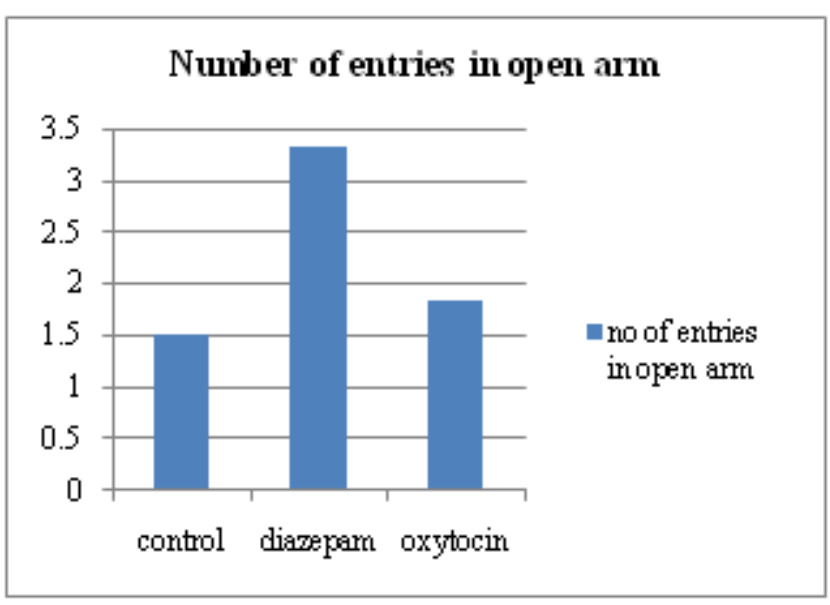

Figure 1

Administration of oxytocin $(4 \mathrm{mcg} / \mathrm{kg})$ to the rats has significant $(\mathrm{p}<.003)$ increase in the frequency of the open arm entries when compared with control group as seen in picture 2 .

\section{Rat entering open arm of elevated plus maze:}

Picture: 2
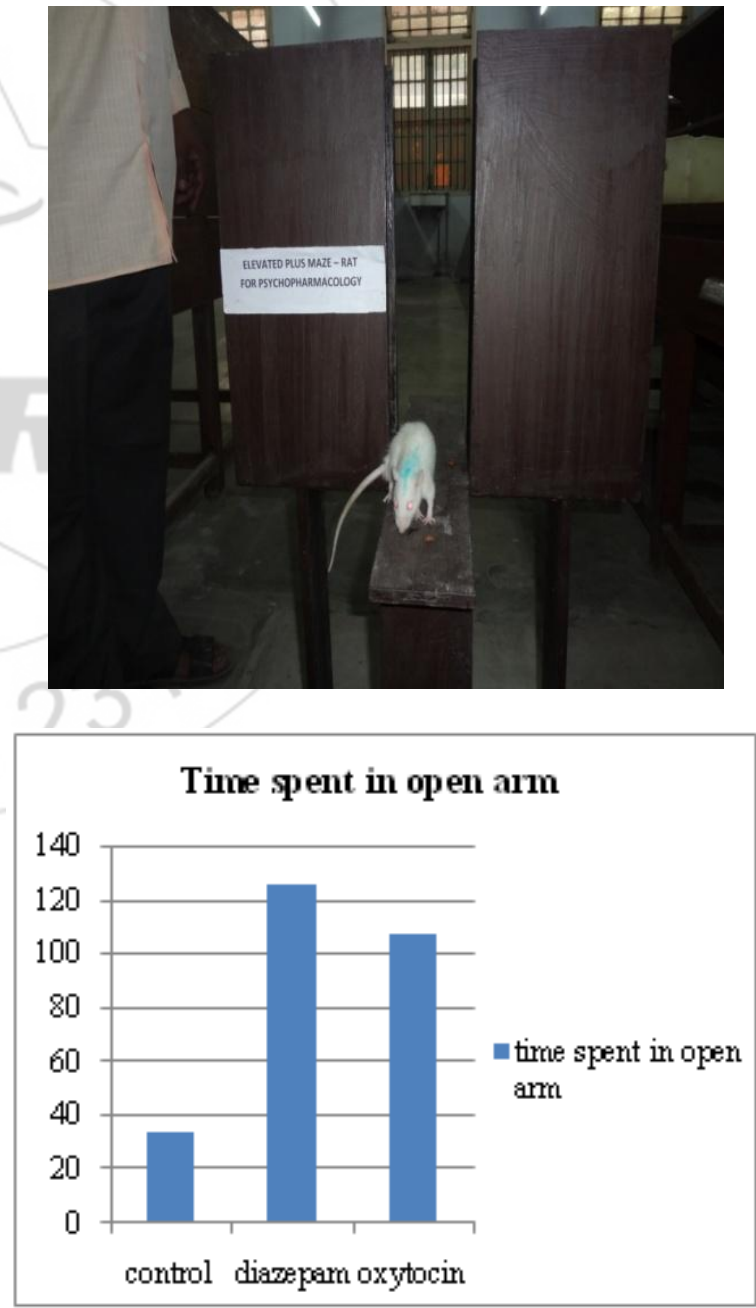

Figure 2

Significant increase in the duration of time spent in the open arm was observed in oxytocin $(4 \mathrm{mcg} / \mathrm{kg})$ treated rats compared with control $(p<0.001)$ and is comparable to that of Diazepam. 
International Journal of Science and Research (IJSR)

ISSN (Online): 2319-7064

Index Copernicus Value (2013): 6.14 | Impact Factor (2015): 6.391

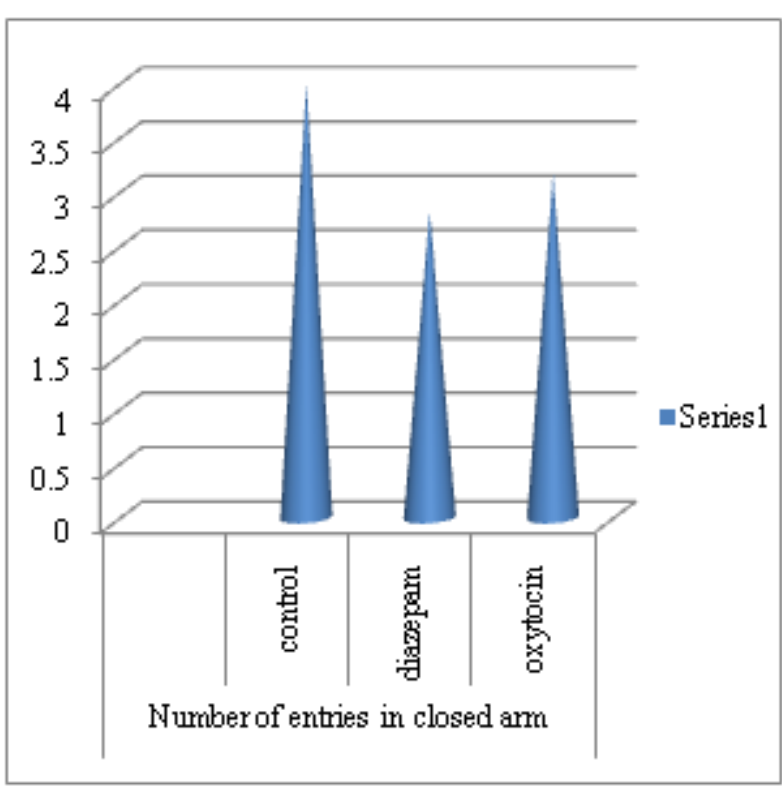

Figure 3: Number of entries in closed arm

Diazepam produce a lowest number of entries in the closed $\operatorname{arm}(\mathrm{p}<.001)$, while control had the highest closed arm entry value of (Figure 3) Number of entries produced by Oxytocin has also decreased when compared with control $(\mathrm{p}<0.001)$

\section{Statistical Analysis}

All analysis was performed using spss software. Datas are analysed using one way ANOVA whenever ANOVA was significant further comparison between vehicle and drug treatment groups were performed by post hock method. The level of significance adopted was $\mathrm{p}<0.05$.

\section{Discussion and Conclusion}

Oytocin has produced increase in time spent in open arm in elevated plus maze. Number of entries into closed arm is also decreased. This shows that there is decreased anxious behavior in the rats compared to control group. Oxytocin is a neuropeptide that can reduce neophobia and improve social affiliation. In vitro, oxytocin induces a massive release of GABA from neurons in the lateral division of the central amygdala which results in inhibition of a subpopulation of peripherally projecting neurons in the medial division of the central amygdala. Common anxiolytics, such as diazepam, act as allosteric modulators of GABA (A) receptors. Because oxytocin and diazepam act on GABAergic transmission, it is possible that oxytocin can potentiate the inhibitory effects of diazepam if both exert their pre, respectively postsynaptic effects on the same inhibitory circuit in the central amygdala. These findings show that oxytocin and diazepam act on different components of the same GABAergic circuit in the central amygdala and that oxytocin can facilitate diazepam effects when used in combination. This raises the possibility that neuropeptides could be clinically used in combination with currently used anxiolytic treatments to improve their therapeutic efficacy. The trust inducing property of oxytocin might help those with social anxiety and depression. Evidence shows it has a novel treatment in autism and schizophrenia ${ }^{16}$
Animal models of anxiety do not intend to replicate all features and symptoms of a specific anxiety disorder but rather generate a state of anxiety that could be related to these disorders. ${ }^{17}$ Hence further evaluation and studies are needed to use oxytocin as an anxiolytic drug.

\section{Acknowledgement}

The authors' are thankful to Dr R Parameswari, MD., Director Institute of Pharmacology, Madurai, Medical college, Madurai, Dr. R. Padmini, MVSc Veterinary Surgeon Central animal house, Madurai Medical college, Madurai, Dr. S. Priya MD, Institute of Community Medicine, Madurai, Medical college, Madurai for their guidance, for providing research facilities, and statistical analysis to carry out the work.

\section{Conflict of Interests}

The authors declare that there is no conflict of interests regarding the publication of this paper.

\section{References}

[1] "Oxytocin". The American society of Health-system pharmacists. Retrieved June 2015.

[2] Corey, E.J. (2012). "Oxytocin". Molecules and Medicine. John Wiley \& Sons. ISBN 9781118361733.

[3] "WHO Model List of Essential Medicines" (PDF). World Health Organization. October 2013. Retrieved 22 April 2014.

[4] Pubchem. OXYTOCIN | C43H66N12012S2-Pub chem." pubchem.ncbi.nlm.nih.gov, retrieved 2015-0725.

[5] Chiras. Daniel D.(2012). Human biology $\left(7^{\text {th }}\right.$ edition).sud-bury. MA; \&Bartlett Learning.p.262.ISBN 9780763783457.

[6] Yang, HP; Wang, wang .SC (2013).Nonsocial function of hypothalamic oxytocin". ISRN neuroscience 2013:179272.doi:10.1155/2013/179272. PMC 4045544. PMID 24967304.

[7] Lee HJ, Macbeth AH, Pagani JH, Young WS (Jun 2009). "Oxytocin: the great facilitator of life". Progress in Neurobiology $\mathbf{8 8} \quad$ (2): $127-51$. doi:10.1016/j.pneurobio.2009.04.001. PMC 2689929. PMID 19482229.

[8] Ross HE, Cole CD, Smith Y, Neumann ID, Landgraf R, Murphy AZ, Young LJ (Sep 2009). "Characterization of the oxytocin system regulating affiliative behavior in female prairie voles". Neuroscience 162 (4): 892-903. doi:10.1016/j.neuroscience.2009.05.055.

PMC 2744157. PMID 19482070.

[9] Huber D, Veinante P, Stoop R (Apr 2005). "Vasopressin and oxytocin excite distinct neuronal populations in the central amygdala". Science $\mathbf{3 0 8}$ (5719): 245-8. doi:10.1126/SCIENCE.1105636. PMID 15821089.

[10] American Psychiatric Association. Diagnostic and statistical manual of mental disorders - DSM-IV-TR ${ }^{-}$. 4th ed. Arlington: American Psychiatric Publishing; 2000 . 


\section{International Journal of Science and Research (IJSR) \\ ISSN (Online): 2319-7064}

Index Copernicus Value (2013): 6.14 | Impact Factor (2015): 6.391

[11](10)3. Kessler RC, Demler O, Frank RG, Olfson M, Pincus HA, Walters EE, et al. Prevalence and treatment of mental disorders, 1990 to 2003. N Engl J Med. 2005;352:2515-23.

[12] Handley SL, Mithani S. Effects of alpha-adrenoceptor agonists and antagonists in a maze-exploration model of 'fear'-motivated behaviour. Naunyn Schmiedebergs Arch Pharmacol. 1984;327:1-5.

[13] 17. Pellow S, File SE. Anxiolytic and anxiogenic drug effects on exploratory activity in an elevated plus-maze: a novel test of anxiety in the rat. Pharmacol Biochem Behav. 1986;24:525-9.

[14] R. Adnaik, P. Pai, V. Sapakal, N. Naikwade, and C. Magdum, "Anxiolytic activity of Vitex negundo linn. in experimental models of anxiety in mice," International Journal of Green Pharmacy, vol. 3, no. 3, pp. 243-247, 2009.

[15] Neuropharmacology. 2010 Jan;58(1):62-8. doi: 10.1016/j.neuropharm.2009.06.039. Epub 2009 Jul 7.

[16] Retrophin (December 2013). "Retrophin Signs U.S. License Agreement for Syntocinon ${ }^{\mathrm{TM}}$ Nasal Spray (Oxytocin)".

[17] Oxytocin: the neuropeptide of love reveals some of its secrets. Lister RG. Ethologically-based animal models of anxiety disorders. Pharmacol Ther. 1990;46:321-40.

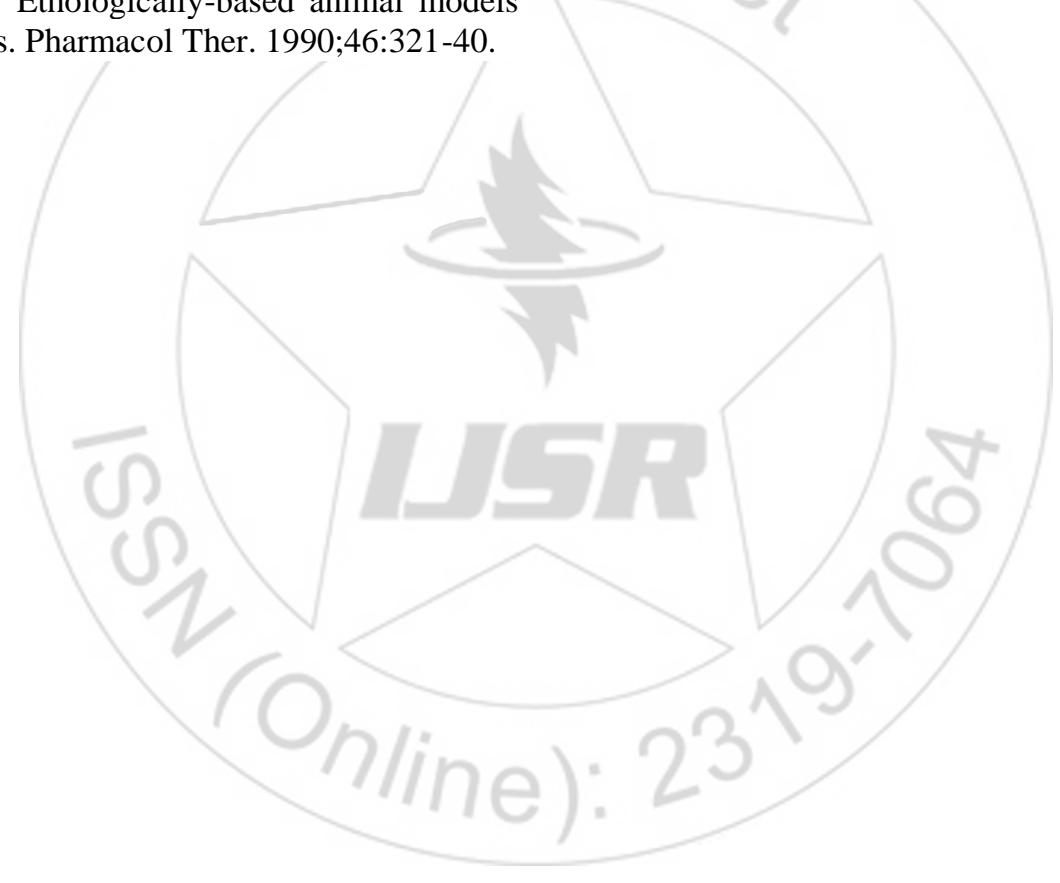

